\title{
Структурные и фотолюминесцентные свойства графитоподобного нитрида углерода
}

\author{
(C) А.В. Баглов ${ }^{1}$, Е.Б. Чубенко ${ }^{1}$, А.А. Гнитько ${ }^{1}$, В.Е. Борисенко ${ }^{1,2}$, А.А. Малашевич ${ }^{3}$, В.В. Углов ${ }^{3}$ \\ ${ }^{1}$ Белорусский государственный университет инорорматики и радиоэлектроники, \\ 220013 Минск, Беларусь \\ ${ }^{2}$ Национальный исследовательский ядерный университет „МИФИ“, \\ 115409 Москва, Россия \\ 3 Белорусский государственный университет, \\ 220030 Минск, Беларусь \\ E-mail: baglov@bsuir.by
}

Поступила в Редакцию 7 октября 2019 г.

В окончательной редакции 15 октября 2019 г.

Принята к публикации 15 октября 2019 г.

\begin{abstract}
Установлена взаимосвязь между структурой и оптическими свойствами полупроводникового графитоподобного нитрида углерода, полученного термической обработкой тиокарбамида в диапазоне температур от 400 до $625^{\circ} \mathrm{C}$ в кислородсодержащей среде. Отмечено смещение максимума полосы фотолюминесценции от 417 к 494 нм при одновременном ее уширении с увеличением температуры синтеза вплоть до $625^{\circ} \mathrm{C}$, что объяснено легированием кислородом, а также образованием дефектов вследствие разложения уже синтезированного материала при повышении температуры.
\end{abstract}

Ключевые слова: графитоподобный нитрид углерода, $g-\mathrm{C}_{3} \mathrm{~N}_{4}$, структура, фотолюминесценция.

DOI: $10.21883 /$ FTP.2020.02.48914.9279

\section{1. Введение}

Графитоподобный нитрид углерода $\left(g-\mathrm{C}_{3} \mathrm{~N}_{4}\right)$, обладая полупроводниковыми свойствами (ширина запрещенной зоны $E_{g} \approx 2.7$ эВ) [1], привлекает внимание исследователей в связи с выраженными фотокаталитическими и люминесцентными свойствами, перспективными для практического использования [2]. Как и графит, объемный $g-\mathrm{C}_{3} \mathrm{~N}_{4}$ имеет слоистую структуру. Каждый слой состоит из плоских три- $s$-триазиновых ячеек. Слои связаны между собой слабыми ван-дер-ваальсовыми силами, что позволяет расщеплять их многочисленными методами (термическая, ультразвуковая, химическая обработка), получая двумерные графеноподобные листы. Значительный интерес к материалу обусловлен простотой синтеза путем термической обработки органических соединений c большой концентрацией азота, например меламина $[3,4]$, цианамида [5], дициандиамида [6], карбамида и тиокарбамида [7].

Ранее было показано, что $g-\mathrm{C}_{3} \mathrm{~N}_{4}$ люминесцирует при комнатной температуре, что перспективно для светоизлучающих структур [8]. Отмечена зависимость положения максимума фотолюминесценции от температуры синтеза материала [9]. Проведенные нами исследования [10] показали принципиальную возможность формирования графитоподобного нитрида углерода в пористых стеклянных матрицах, что актуально для его практического фотокаталитического применения. Установлено также легирование $g-\mathrm{C}_{3} \mathrm{~N}_{4}$ кислородом [11] в процессе синтеза в диапазоне температур $450-550^{\circ} \mathrm{C}$. Однако совокупность имеющихся экспериментальных данных не позволяет однозначно определить зависимость физико- химических свойств получаемого материала от условий синтеза. Таким образом, целью наших исследований являлась оценка влияния температуры синтеза $g-\mathrm{C}_{3} \mathrm{~N}_{4}$ из тиокарбамида в диапазоне $400-625^{\circ} \mathrm{C}$ на его структурные и люминесцентные свойства.

\section{2. Методика подготовки и исследования образцов}

В очищенный керамический тигель объемом 20 мл помещали 2 г тиокарбамида, $\mathrm{CS}\left(\mathrm{NH}_{2}\right)_{2}$, марки ЧДА с последующей механической герметизацией для уменьшения истечения газов из тигля в процессе разложения прекурсора, а также для ограничения доступа воздуха к синтезированному материалу. Термообработку проводили в муфельной печи в течение 30 мин при фиксированной температуре в диапазоне $400-625^{\circ} \mathrm{C}$. Средняя скорость нагрева печи от комнатной температуры до температуры синтеза составляла $12^{\circ} \mathrm{C} /$ мин. После проведения процесса синтеза печь остывала естественным путем до температуры, близкой к комнатной.

Морфологию полученного материала исследовали с помощью растровой электронной микроскопии (РЭМ) на микроскопе Hitachi S-4200. Для определения кристаллической структуры и фазового состава использовали рентгенодифракционный анализ (РДА), измерения проводили на дифрактометре ДРОН-4 (длина волны излучения $\lambda=0.154184 \mathrm{Hм}$ ). Химические связи в материале изучали с помощью инфракрасной спектроскопии с преобразованием Фурье (FTIR) с использованием спектрометра Bruker Vertex 70 FTIR. Фотолюминесценцию 

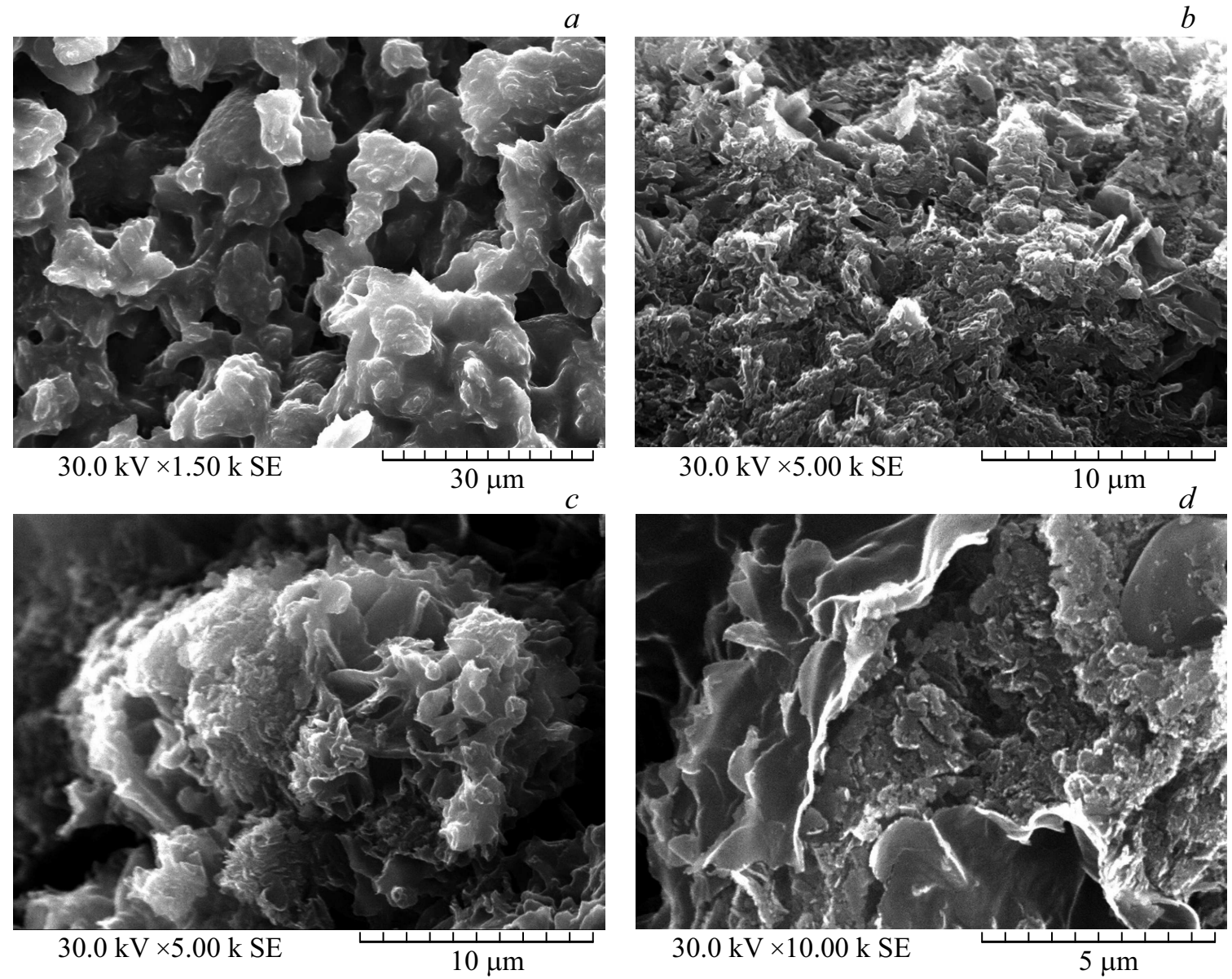

Рис. 1. Поверхность материала, синтезированного термообработкой тиокарбамида в течение 30 мин при $450(a), 500(b), 550(c)$, $600^{\circ} \mathrm{C}(d)$.

материала исследовали при комнатной температуре в условиях ее возбуждения монохроматическим излучением с длиной волны 345 нм, который выделялся из спектра излучения ксеноновой лампы мощностью 1 кВт с использованием монохроматора SolarTII DM 160. Спектр фотолюминесценции регистрировали монохроматоромспектрографом Solar TII MS 7504i, оснащенным кремниевой ПЗС-матрицей.

\section{3. Результаты}

Структура поверхности синтезированного материала показана на рис. 1. Термическая обработка тиокарбамида при 400 и $450^{\circ} \mathrm{C}$ приводит к образованию мелкодисперсного материала, состоящего из частиц размером $\sim 20$ мкм с оплавленной поверхностью и промежутками $\sim 15$ мкм между ними (рис. $1, a$ ). В свою очередь они образованы частицами размером 3-5 мкм. Увеличение температуры приводит к уплотнению структуры и переходу от крупнозернистой структуры к смешанной, представляющей собой пластинки толщиной 500-700 нм, встроенные в субмикрометровые зерна (рис. $1, a-d)$.
Проведенный рентгенодифракционный анализ показывает, что синтезированный материал представляет собой $g-\mathrm{C}_{3} \mathrm{~N}_{4}$, типичный спектр приведен на рис. 2. Наблюдаются характерные пики при углах 13.2, 27.7, 44.2, 57.1

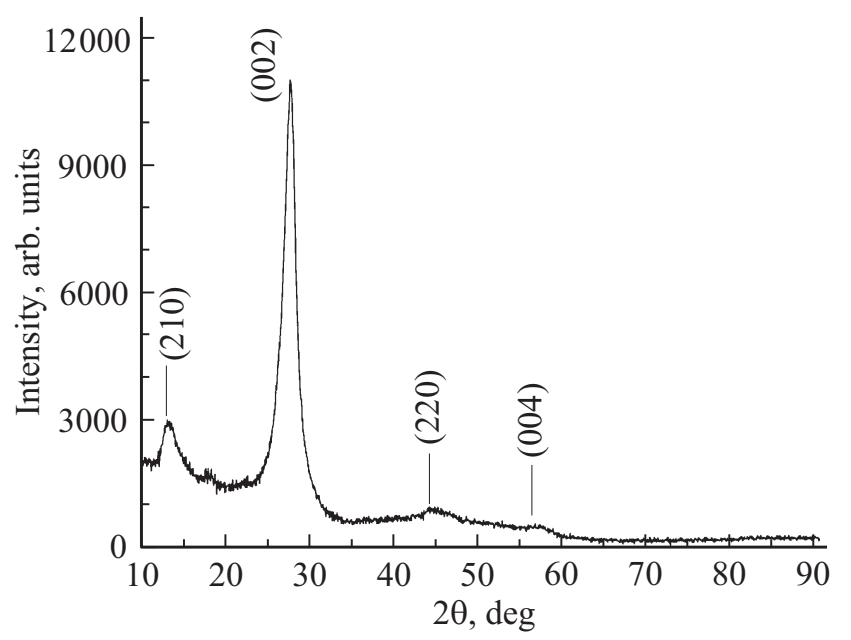

Рис. 2. Дифрактограмма $g-\mathrm{C}_{3} \mathrm{~N}_{4}$, синтезированного в течение 30 мин при $500^{\circ} \mathrm{C}$. 


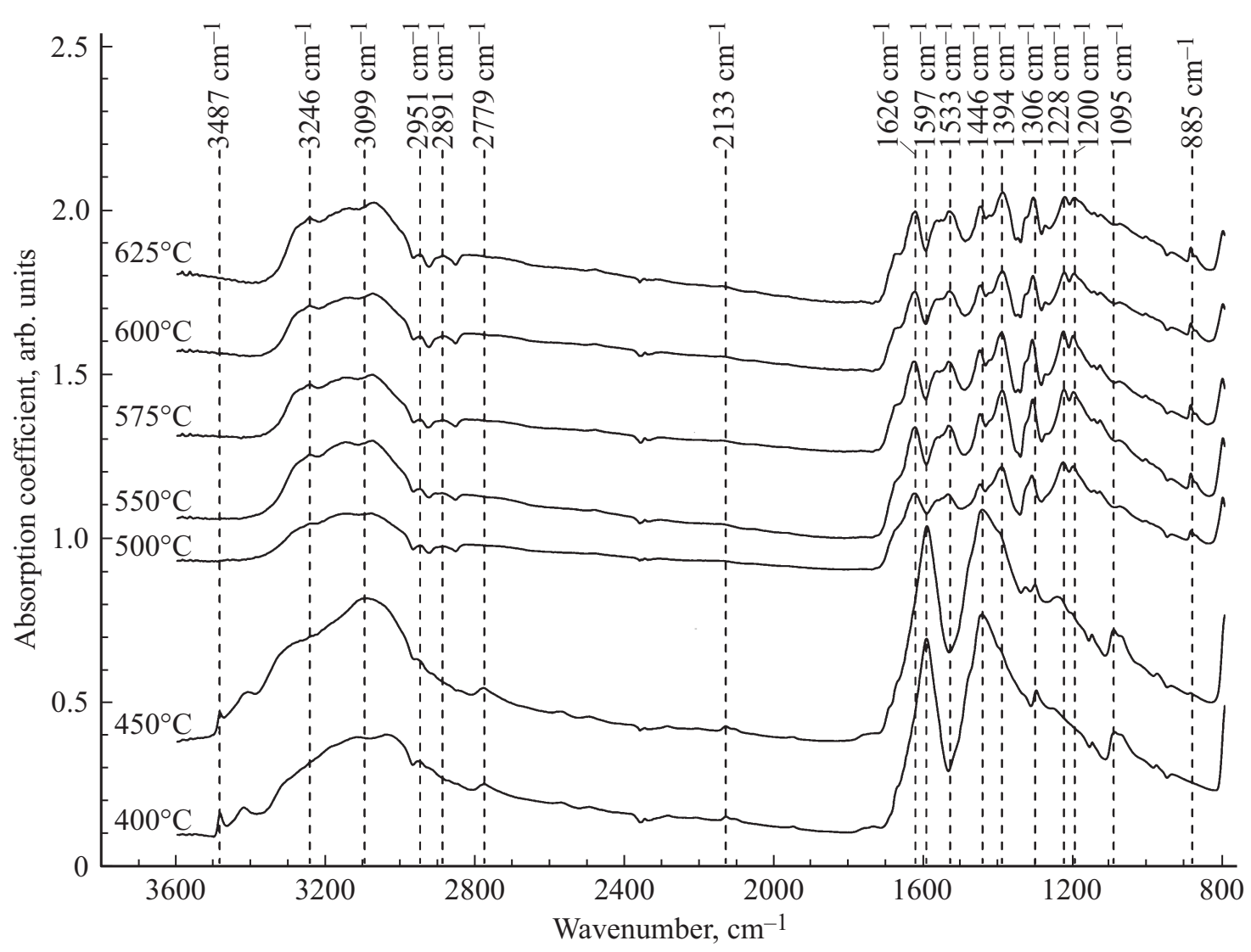

Pис. 3. FTIR-спектры материала, синтезированного из тиокарбамида при различных температурах (указаны) в течение 30 мин.

связанные с кристаллографическими плоскостями (210), (002), (220), (004) g- $\mathrm{C}_{3} \mathrm{~N}_{4}$ соответственно [12]. Размер кристаллитов составляет $\sim 5$ нм для (210) и (002).

Результаты исследования синтезированного при различных температурах материала методом инфракрасной спектроскопии с преобразованием Фурье, показанные на рис. 3, также подтверждают образование $g-\mathrm{C}_{3} \mathrm{~N}_{4}$. Так, поглощение в диапазоне $2700-3500 \mathrm{~cm}^{-1}$ обычно относят к связям $\mathrm{O}-\mathrm{H}$ и $\mathrm{N}-\mathrm{H}$ [13]. Также отметим, что пики из этого диапазона вблизи 2900 и $3100 \mathrm{~cm}^{-1}$ соответствуют $s p^{3}$ - и $s p^{2}$-гибридизации связей $\mathrm{C}-\mathrm{H}$ [14]. За слабый пик при $2133 \mathrm{~cm}^{-1}$ отвечают связи $\mathrm{C}-\mathrm{N}$ или $\mathrm{N}=\mathrm{C}=\mathrm{N}[13,15]$, обусловленные либо частичным разложением $g-\mathrm{C}_{3} \mathrm{~N}_{4}[13]$, либо неполной полимеризацией прекурсора [15]. Диапазон 1200-1600 cм-1 обычно связан с характерными колебательными модами гетероциклов $\mathrm{C}-\mathrm{N}$ [12]. Отметим, что в спектрах образцов, синтезированных при 400 и $450^{\circ} \mathrm{C}$, наблюдается пики при 1095 и $2779 \mathrm{~cm}^{-1}$, отсутствующие в образцах с более высокой температурой синтеза. Мы полагаем, что они связаны с остатками тиокарбамида [16] в синтезируемом материале, которые с ростом температуры удаляются из материала.

Также отметим наличие пика на $885 \mathrm{~cm}^{-1}$, присутствующего в спектре образцов, синтезированных при температурах $500^{\circ} \mathrm{C}$ и выше, связанного с образованием мелама и мелема - промежуточных соединений в полимеризации нитрида углерода [17].

Все синтезированные образцы характеризуются интенсивной фотолюминесценцией. Спектры фотолюминесценции приведены на рис. 4. Интенсивность фотолюминесценции с ростом температуры синтеза материала убывает, достигает минимума при $600^{\circ} \mathrm{C}$ и несколько увеличивается при $625^{\circ} \mathrm{C}$. Также отметим уширение полосы фотолюминесценции с ростом температуры до $500^{\circ} \mathrm{C}$ и выше.

Положения максимумов полос фотолюминесценции, их полная ширина на половине высоты (full width at half maximum, FWHM) приведены в таблице.

С ростом температуры синтеза от 400 до $600^{\circ} \mathrm{C}$ происходит монотонное снижение интенсивности с неболь-

Положение максимума и полная ширина на половине высоты полос фотолюминесценции материалов, полученных при различных температурах

\begin{tabular}{l|c|c|c|c|c|c|c}
\hline $\begin{array}{l}\text { Температура } \\
\text { синтеза, }{ }^{\circ} \mathrm{C}\end{array}$ & 400 & 450 & 500 & 550 & 575 & 600 & 625 \\
\hline $\begin{array}{l}\text { Положение } \\
\text { максимума, нм }\end{array}$ & 417 & 453 & 456 & 468 & 490 & 494 & 494 \\
\hline FWHM, нм & 78.3 & 66.3 & 69.6 & 94.9 & 126.3 & 132.4 & 130.3
\end{tabular}




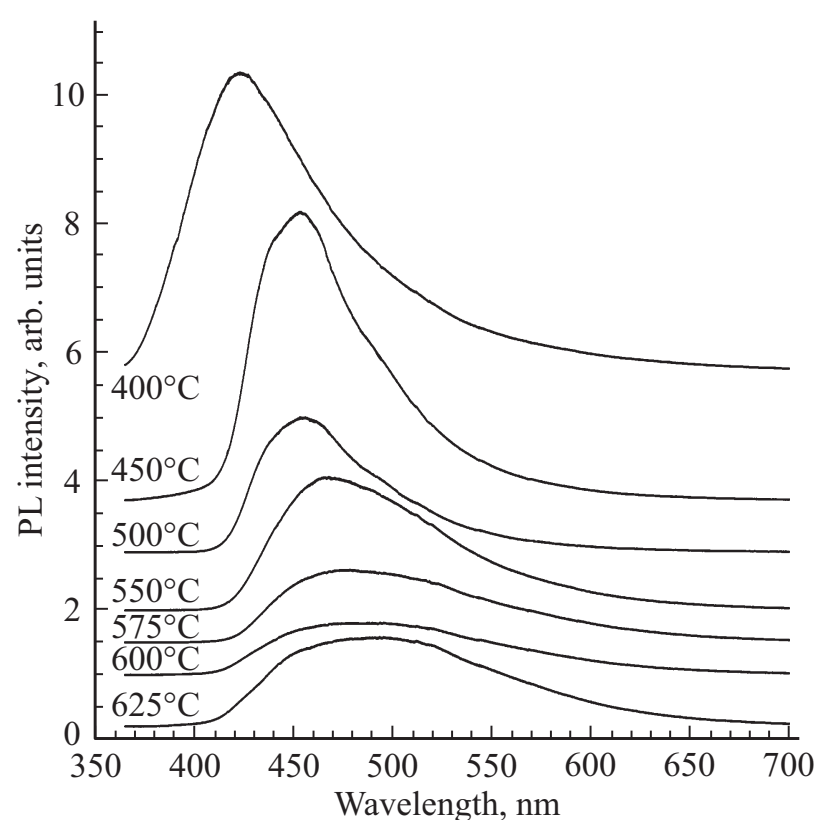

Рис. 4. Спектры фотолюминесценции (PL) материала, синтезированного из тиокарбамида при различных температурах в течение 30 мин.

шим увеличением при $625^{\circ} \mathrm{C}$. Положение максимума при этом смещается с 417 нм при температуре синтеза $400^{\circ} \mathrm{C}$ до 494 нм при температурах синтеза 600 и $625^{\circ} \mathrm{C}$. Полная ширина на половине амплитуды увеличивается с 66.3 до 132.4 (130.3) нм при возрастании температуры синтеза от 450 до $600^{\circ} \mathrm{C}\left(625^{\circ} \mathrm{C}\right)$ соответственно. Такой результат связан со сложным строением полосы фотолюминесценции, возникающим вследствие формирования двумерной и объемной форм $g-\mathrm{C}_{3} \mathrm{~N}_{4}$, увеличения количества дефектов и примесей в процессе перестройки материала, энергетические уровни которых лежат на 0.2-0.5 эВ ниже дна зоны проводимости. Установленные закономерности позволяют рекомендовать температуру синтеза $450-500^{\circ} \mathrm{C}$ в качестве оптимальной с точки зрения достижения наилучших люминесцентных характеристик.

\section{4. Заключение}

Экспериментально установлено формирование графитоподобного нитрида углерода путем термической обработки тиокарбамида в диапазоне температур $400-625^{\circ} \mathrm{C}$ в условиях ограниченного доступа кислородсодержащей атмосферы. Согласно результатам рентгенодифракционного анализа, доминирующей ориентацией кристаллитов синтезированного материала является [002]. Исследование методом инфракрасной спектроскопии с преобразованием Фурье показывает, что при температуре синтеза $<500^{\circ} \mathrm{C}$ происходит неполное удаление прекурсора из объема материала, что подтверждается наличием пиков при 2779 и $1095 \mathrm{~cm}^{-1}$. В диапазоне температур
500-625 ${ }^{\circ} \mathrm{C}$ синтезируется материал с близкими FTIRспектрами, на которых присутствует пик, связанный с образованием мелама и мелема - промежуточных соединений в полимеризации нитрида углерода. Наличие пиков, связанных с $s p^{2}$ - и $s p^{3}$-гибридизацией, свидетельствует о наличии $g-\mathrm{C}_{3} \mathrm{~N}_{4}$ в двумерном виде $\left(s p^{2}\right.$-гибридизация) на поверхности объемного материала $\left(s p^{3}\right.$-гибридизация).

Отмеченные по FTIR-данным химические связи с кислородом и признаки нестехиометричности позволяют связать наблюдающиеся изменения в спектрах фотолюминесценции с легированием синтезируемого материала кислородом, а также с образованием дефектов вследствие разложения уже синтезированного $g-\mathrm{C}_{3} \mathrm{~N}_{4}$ при повышении температуры. Установленные закономерности позволяют рекомендовать температуру синтеза $450-500^{\circ} \mathrm{C}$ в качестве оптимальной с точки зрения достижения наилучших люминесцентных характеристик.

\section{Финансирование работы}

Работа выполнена в рамках ГПНИ Республики Беларусь „Конвергенция-2020“ (задание 3.05), ГПНИ Республики Беларусь „Материаловедение и технологии материалов“ (задание 1.56) и гранта Министерства образования Республики Беларусь для докторантов.

\section{Благодарности}

Авторы выражают благодарность Д.В. Жигулину за электронно-микроскопический анализ образцов, а также C.M. Завадскому за помощь в проведении анализа синтезированных материалов методом инфракрасной спектроскопии с преобразованием Фурье.

\section{Конфликт интересов}

Авторы заявляют, что у них нет конфликта интересов.

\section{Список литературы}

[1] S. Chu, Y. Wang, Y. Guo, J. Feng, C. Wang, W. Luo, X. Fan, Z. Zou. ACS Catal., 3, 912 (2013).

[2] A. Thomas, A. Fischer, F. Goettmann, M. Antonietti, J.-O. Müller, R. Schlögl, J. Carlsson. J. Mater. Chem., 18, 4893 (2008).

[3] S.C. Yan, Z.S. Li, Z.G. Zou. Langmuir, 25, 10397 (2009).

[4] Е.Б. Чубенко, А.В. Баглов, Е.С. Лисимова, В.Е. Борисенко. Мокеровские чтения: сб. тр. (М., НИЯУ МИФИ, 2019) c. 81 .

[5] J. Yuan, X. Liu, Y. Tang, Y. Zeng, L. Wang, S. Zhang, T. Cai, Y. Liu, S. Luo, Y. Pei, C. Liu. Appl. Catal. B, 237, 24 (2018).

[6] M. Zhang, J. Xu, R. Zong, Y. Zhu. Appl. Catal. B, 147, 229 (2014).

[7] F. Dong, Z. Zhao, T. Xiong, Z. Ni, W. Zhang, Y. Sun, W.-K. Ho. ACS Appl. Mater. Interfaces, 5, 11932 (2013).

[8] Y. Zhang, Q. Pan, G. Chai, M. Liang, G. Dong, Q. Zhang, J. Qiu. Sci. Rep., 3, 1943 (2013). 
[9] D. Das, S.L. Shinde, K.K. Nanda. ACS Appl. Mater. Interfaces, 8, 2181 (2016)

[10] E.B. Chubenko, A.V. Baglov, E.S. Lisimova, V.E. Borisenko. Int. J. Nanosci., 18, 1940042 (2019).

[11] N.M. Denisov, E.B. Chubenko, V.P. Bondarenko, V.E. Borisenko. Tech. Phys. Lett., 45, 108 (2019).

[12] F. Fina, S.K. Callear, G.M. Carins, J.T.S. Irvine. Chem. Mater., 27, 2612 (2015).

[13] J. Fu, B. Zhu, C. Jiang, B. Cheng, W. You, J. Yu. Small, 13, 1603938 (2017).

[14] G. Lazar, K. Zellama, I. Vascan, M. Stamate, I. Lazar, I. Rusu. J. Optoelectron. Adv. Mater., 7, 647 (2005).

[15] Y. Li, F. Wei, Y. Liu, H. Zhao, X.-N. Ren, J. Liu, T. Hasan, L. Chen, B.-L. Su. Nanoscale, 10, 4515 (2018).

[16] Интернет-ресурс: Национальный институт стандартов и технологий США. https://webbook.nist.gov/cgi/cbook.cgi? $\mathrm{ID}=\mathrm{C} 62566 \&$ Mask $=80 \# \mathrm{IR}-\mathrm{Spec}$

[17] E. Wirnhier, M.B. Mesch, J. Senker, W. Schnick. Chem. Eur. J., 19, 2041 (2013).

Редактор Л.В. Шаронова

\section{Structural and photoluminescent properties of graphite-like carbon nitride}

A.V. Baglov ${ }^{1}$, E.B. Chubenko ${ }^{1}$, A.A. Hnitsko ${ }^{1}$, V.E. Borisenko ${ }^{1,2}$, A.A. Malashevich ${ }^{3}$, V.V. Uglov ${ }^{3}$

${ }^{1}$ Belarusian State University

of Informatics and Radioelectronics,

P. Browka str., 6, 220013 Minsk, Republic of Belarus

2 National Research Nuclear University MEPhl,

115409 Moscow, Russia

${ }^{3}$ Belarusian State University, 220030 Minsk, Belarus

Abstract The relationship between the structure and optical properties of semiconductor graphite-like carbon nitride obtained by heat treatment of thiocarbamide in the temperature range from 400 to $625^{\circ} \mathrm{C}$ in an oxygen-containing medium is established. A shift of the maximum of the photoluminescence band from 417 to $494 \mathrm{~nm}$ was noted with its simultaneous broadening with increasing synthesis temperature up to $625^{\circ} \mathrm{C}$, which is explained by doping with oxygen, as well as the formation of defects due to decomposition of already synthesized material with increasing temperature. 